\title{
Numerical Study on the Effects of the Wick Structure of an Annular Heat Pipe on the Isothermal Performance
}

\author{
Hongzhe Zhang ${ }^{1}$, Fang Ye ${ }^{1 *}$, Hang Guo ${ }^{1}$, Xiaoke Yan $^{2}$, Chongfang Ma ${ }^{1}$ \\ ${ }^{1}$ MOE Key Laboratory of Enhanced Heat Transfer and Energy Conservation, and Beijing Key Laboratory of Heat Transfer \\ and Energy Conversion, College of Environmental and Energy Engineering, Beijing University of Technology \\ Beijing 100124, China \\ ZhangHongZhe@emails.bjut.edu.cn; yefang@bjut.edu.cn \\ ${ }^{2}$ National Institute of Metrology (NIM) \\ Beijing 100013, China
}

\begin{abstract}
This paper presents a numerical work on the effect of wick construction on the isothermal performance of an annular heat pipe. Two type connection wick structures were designed, the axial direction connection wick structure and radial direction connection wick structure. A three-dimensional symmetrical model with liquid-vapor phase transition was built. The isothermal performance of the annular part at the front end of the heat pipe was good, the temperature of liquid pool part was about 5-6 K higher than the annular part, and the isothermal performance of axial direction connection wick structure is better than radial direction connection wick structure. The influence of the wick on the vapor flow will affect the vapor temperature distribution, the isothermal surface distribution is obviously the same as the form of the axial direction connection wick at the outlet of the liquid pool, and the isothermal surface will rotate with the axial direction connection wick structure.
\end{abstract}

Keywords: Annular heat pipe; Three-dimensional model; Liquid-vapor phase transition; Isothermal performance; Potassium.

\section{Introduction}

Heat pipes have very strong heat transfer ability through phase transition of working fluids. Unlike heat transfer through sensible heat, the heat pipes transfer heat depends on the latent heat of evaporation and condensation of the working fluids. Therefore, as a heat transfer device, heat pipes have following advantages: high heat transfer capacity, fast thermal response, high isothermal performance and high reliability. Usually, there are no moving parts inside the heat pipe, the vapor flow were drive by very small pressure difference, so heat pipes could transfer a large amount of heat at a very small temperature difference. Due to high heat transfer performance, heat pipes have been widely used in high temperature and high thermal density heat transfer fields, such as electronic component cooling [1-2], high temperature waste heat recovery [3], residual heat removal [4], aircraft thermal protection [5], solar thermal utilization [6] and other fields.

In the other hand, the isothermal performance is very good when the heat pipe works stably because the vapor generated by the working fluid is saturated vapor. According to the Clausius-Clapeyron equation, the temperature of the working fluid varies little when the working pressure changes little. Therefore, heat pipes were also used in field of measurement. Gascontrolled heat pipes are used to calibrate the temperature measuring elements by providing a stable and uniform temperature zone [7-8]. Compare with heat pipes for heat transfer, the length diameter ratio of gas-controlled heat pipe or other heat pipe for metering is small, and there is a pressure control system in particular. The isothermal performance and temperature stability of gas-controlled heat pipes are much better than other heat pipes due to the pressure control system [9]. The inert gas of the pressure control system is directly connected with the inner part of the heat pipe, and the pressure of the working fluid of the heat pipe is adjusted by controlling the pressure of the inert gas.

Although the isothermal performance, temperature stability and service life of the gas-control heat pipe are very good [10], the pressure control system is complex and the heat pipe manufacturing is difficult [11]. Annular heat pipes are also widely used in the field of measurement. Annular heat pipes are more effective than conventional heat pipes and can be used in many applications due to the annular structure [12-13]. For different conditions, the annular heat pipe can be heated at one side and cooled at the other side as the cylinder heat pipe to transfer a lot of heat [12-13], or heated at the outer pipe and cooled at the inner pipe to provide a uniform temperature zone [14-16]. The annular heat pipe is mainly used as a temperature 
stabilizing device to reduce the influence of the heating equipment on the stability of temperature distribution in the field of measurement [17-18]. Annular heat pipes are usually used with freezing points such as aluminium or silver freezing points. The heat source heated the outer wall of the outer pipe of annular heat pipe, the temperature of the freezing point can be maintained at the melting point in the inner pipe of annular heat pipe when the freezing point is in the solid-liquid mixing state [18].

In this study, two types model were designed, including axial direction connection wick structure and radial direction connection wick structure. Three-dimensional symmetrical models were built to study the internal temperature distribution of an annular heat pipe with different wick structures.

\section{Heat pipe structure}

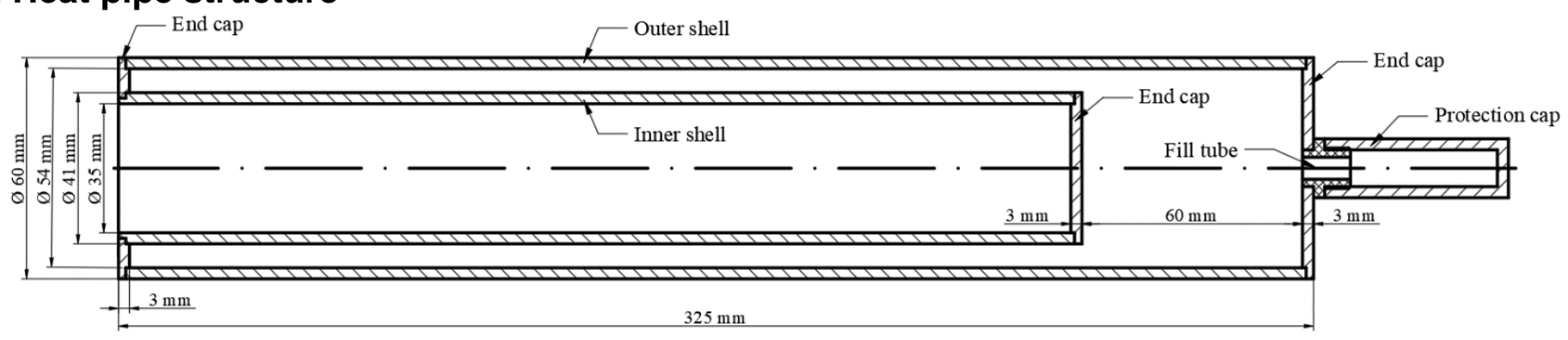

Fig. 1: Cross-sectional drawing of the annular heat pipe

A concentric annular heat pipe was designed to provide an isothermal zone of more than $750 \mathrm{~K}$. The schematic diagram of the concentric annular heat pipe is shown in Fig. 1. When concentric annular the heat pipe works, the whole outer surface of the outer pipe is heated, and the melting point in the inner pipe of annular heat pipe. There was liquid pool at the end of annular heat pipe, it was used to store working fluid when the annular heat pipe is not working.

The working fluid was potassium and the mass of working fluid is $100 \mathrm{~g}$. In order to reduce the corrosion of working fluid to heat pipe, the material of all parts of the heat pipe was Inconel alloy 600. There are some research on the vertical placement of the annular heat pipe [17-18], this paper studies the working status when the annular heat pipe is placed horizontally. The annular heat pipe is in the design stage, the simulation is mainly used to verify the current design and provide specific data for the actual manufacturing of annular heat pipe. In order to stabilize the operation of the working fluid in the annular heat pipe, the liquid working fluid should flow in the wick to reduce the drop from the wall of the inner pipe. Therefore, in addition to the wicks on the inner and outer pipe walls, a wick structure is also needed to connect the inner and outer pipe walls. Two kinds wick structures are designed in this study, the axial direction connection wick structures (model 1) and the radial direction connection wick structures (model 2). Two layers of Inconel alloy 600 screen mesh were used as wick.

\section{Numerical Model}

\subsection{Computation area}

Two three-dimensional symmetrical models base on the COMSOL Multiphysics software were built to study the influence of wick structure on the flow of working fluid in the concentric annular heat pipe. To reduce the amount of calculation, the models mainly studied the flow process of working fluid, so the calculation area did not include the heat pipe wall, fill tube and protection cap.

The axial direction connection wick structures are more common in literatures, but most of the literature studies the heat transfer performance of annular heat pipe when it is placed vertically. A radial direction connection wick structure was design for the annular heat pipe when it is placed horizontally. The computation area of two symmetric numerical models are shown in Fig. 2. The axial cross-sectional of axial direction connection wick structure and the axial crosssectional of axial direction connection wick structure are shown in Fig. 3. Because model 1 is not centrosymmetric, after affected by gravity, the heat transfer and fluid flow performance of the heat pipe may change when the heat pipe rotates 
along the axial direction. So after rotating the wick $60^{\circ}$ of model 1 , model 3 was studied too. The structure of model 3 is shown in Fig. 4.

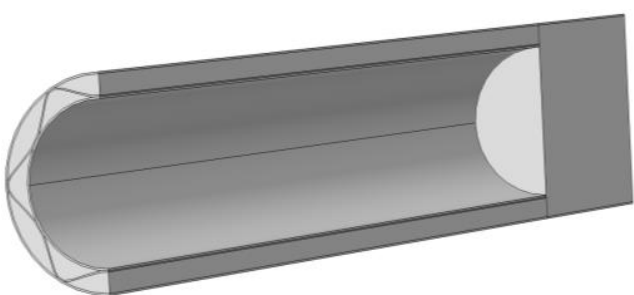

(a) Axial direction connection wick structure (model 1)

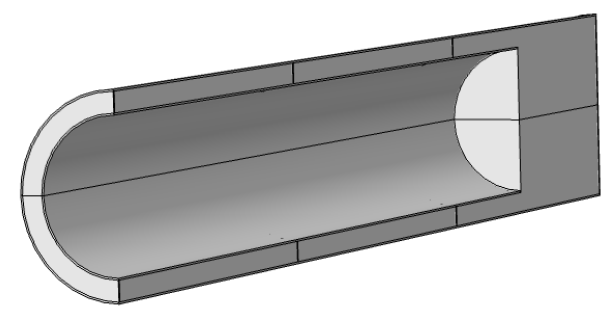

(b) Radial direction connection wick structure (model 2) Fig. 2: Computation area of two symmetric numerical model

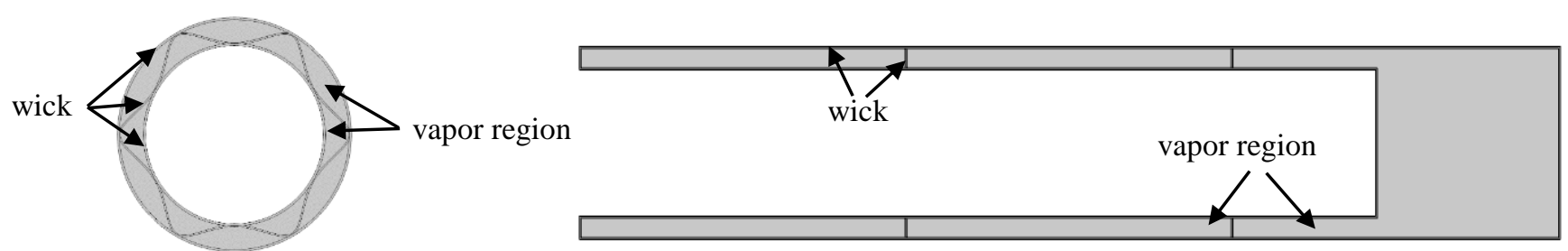

(a) Axial direction connection wick structure (model 1)

(b) Radial direction connection wick structure (model 2)

Fig. 3: Cross-sectional of the annular heat pipe wick

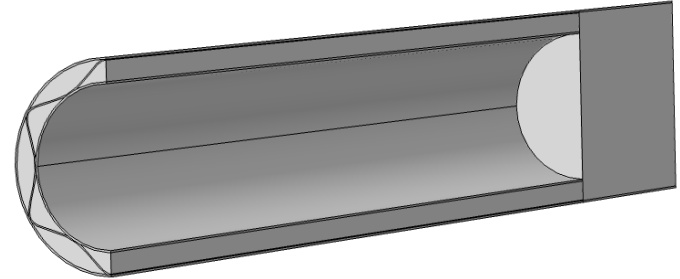

(a) Computation area (model 3)

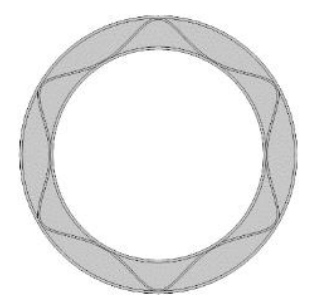

(b) Cross-sectional (model 3)

Fig. 4: Structure of an axial direction connection wick structure (model 3)

\subsection{Governing equations}

In some literatures, the position of phase transformation is set on the surface of the wick contacting with the vapor, and the liquid working fluid in the wick and the vapor in the vapor region are both single-phase flow [4, 19]. This model can simulate the heat transfer well, but the prediction accuracy of the temperature distribution in the heat pipe is not as good as that of the model with phase change in the vapor region [20]. The conservation equations of mass, momentum and energy can be written as follows:

$$
\begin{gathered}
\frac{\partial \rho}{\partial t}+\nabla \cdot(\rho \mathbf{u})=0 \\
\rho\left(\frac{\partial}{\partial t}+\mathbf{u} \cdot \nabla\right) \mathbf{u}=-\nabla p-\nabla \cdot\left[\left(\mu\left(\nabla \cdot \mathbf{u}+\nabla \cdot \mathbf{u}^{\mathrm{T}}\right)\right)\right]+\rho \mathbf{g}-\left(\frac{\mu \varepsilon}{K}\right) \mathbf{u}-\frac{C_{E}}{\sqrt{K}} \rho|\mathbf{u}| \mathbf{u} \\
\rho C_{p} \frac{\partial T}{\partial t}+\rho C_{p} \mathbf{u} \cdot \nabla T=\nabla \cdot(k \nabla T)+Q_{p}-m_{l v} \Delta H_{l v}
\end{gathered}
$$
laminar.

In the vapor region, $K=\infty$ and $\varepsilon=1 . C_{E}$ is the fluid inertia drag coefficient, its value is zero when the fluid is 
Lee's model [21] was used to deal with the mass transfer process in vapor-liquid two-phase flow. The volume fraction equations of vapor and mass transfer equation of vapor can be written as follows:

$$
\begin{gathered}
\frac{\partial \phi_{v}}{\partial t}+\nabla \cdot\left(\phi_{v} \mathbf{u}_{v}\right)=\nabla \cdot\left(\frac{D_{m d}}{\phi_{v}} \nabla \phi_{v}\right)+\frac{m_{l v}}{\rho_{v}} \\
m_{l v}=\left\{\begin{array}{cl}
f_{\text {evap }} \phi_{l} \rho_{l} \frac{T-T_{\text {sat }}}{T_{\text {sat }}} & T \geq T_{\text {sat }} \text { and } \phi_{v}<1 \\
f_{\text {cond }} \phi_{v} \rho_{v} \frac{T_{\text {sat }}-T}{T_{\text {sat }}} & T<T_{\text {sat }} \text { and } \phi_{l}<1 \\
0 & \text { otherwise }
\end{array}\right.
\end{gathered}
$$

The $f_{\text {evap }}$ and $f_{\text {cond }}$ are the mass transfer coefficient in evaporation and condensation. This is an empirical constant. If the value is too large, it is easy to cause oscillation, the numerical results are not easy to converge. If the value is too small, the value error between the phase transition interface and the saturation temperature increases. The value of $f_{\text {evap }}$ and $f_{\text {cond }}$ were both sat as $0.1 \mathrm{~s}^{-1}[20]$.

There are only vapor and liquid phases in vapor region. The physical parameters of mixed phase can be calculated by:

$$
\begin{gathered}
\phi_{v}+\phi_{l}=1 \\
\rho=\phi_{v} \rho_{v}+\phi_{l} \rho_{l} \\
c_{p}=\phi_{v} c_{p v}+\phi_{l} c_{p l} \\
k=\phi_{v} k_{v}+\phi_{l} k_{l} \\
\mu=\phi_{v} \mu_{v}+\phi_{l} \mu_{l}
\end{gathered}
$$

In the wick, the mesh number is 80 and two layers flat type screen mesh wick with a total thickness of $0.5 \mathrm{~mm}$ are measured. The porosity and permeability of the wick are 0.588 and $3.96 \times 10^{-11} \mathrm{~m}^{2}$ respectively calculated by following equations [19]:

$$
\begin{gathered}
\varepsilon=1-\frac{1.05 \pi N d_{w}}{4} \\
K=\frac{d_{w}^{2} \varepsilon^{2}}{122(1-\varepsilon)^{2}}
\end{gathered}
$$
[19]:

The wick is modelled using conduction heat transfer only using an effective heat transfer considering the porosity

$$
\begin{gathered}
k=k_{l}\left[\frac{\left(k_{l}+k_{w}\right)+(1-\varepsilon)\left(k_{l}-k_{w}\right)}{\left(k_{l}+k_{w}\right)-(1-\varepsilon)\left(k_{l}-k_{w}\right)}\right] \\
\rho=\varepsilon \rho_{l} \\
c_{p}=(1-\varepsilon) c_{p w}+\varepsilon c_{p l}
\end{gathered}
$$

\subsection{Boundary conditions}

A non-slip boundary condition is imposed at the outer surface of outer pipe and the inner surface of inner pipe of the annular heat pipe as the evaporator section and condenser section respectively. Evaporator section and condenser 
section of the numerical models are shown in Fig. 5. Refer to our previous experimental experience, the constant heat flux is defined at the wall boundaries of both evaporator section and condenser section. Other external surfaces of annular heat pipe are the adiabatic surface. The initial temperature and pressure of the calculation domain are $850 \mathrm{~K}$ and $1.28 \mathrm{kPa}$ respectively.

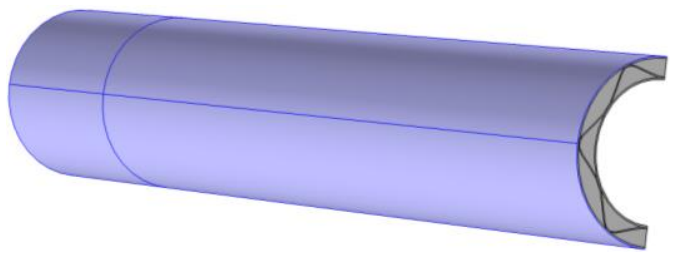

(a) Evaporator section

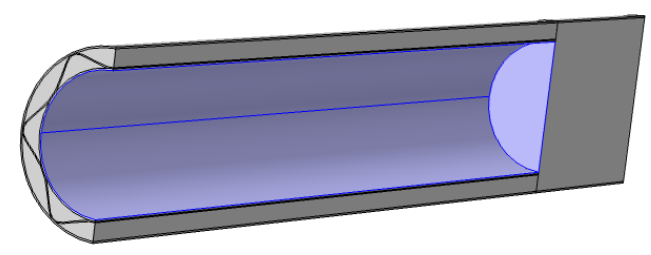

(b) Condenser section

Fig. 5: Evaporator section and condenser section of the numerical models

\subsection{Numerical simulation}

The working fluid is potassium, and the physical parameters are found in the manual of metal physical properties. A temperature of $900 \mathrm{~K}$ is used as the boiling temperature and once the saturation temperature $(900 \mathrm{~K})$ is reached, evaporation starts and phase change occurs. The mass of working fluid is $100 \mathrm{~g}$, so the height of liquid level can be calculated as $14 \mathrm{~mm}$.

The governing equations are discretised using a finite element analysis approach. A combination of the SIMPLE algorithm for pressure-velocity coupling and a first-order upwind scheme for the determination of momentum and energy is included in the model. PRESTO discretization for the volume fraction and pressure interpolation scheme. The time step has been selected based on the Courant number.

\section{Results and Discussion}

The simulation results of the annular heat pipe reached a quasi-steady state after around $90 \mathrm{~s}$. The isothermal surface inside the annular heat pipe is shown in Fig. 6.

Isothermal surface $(\mathrm{K})$

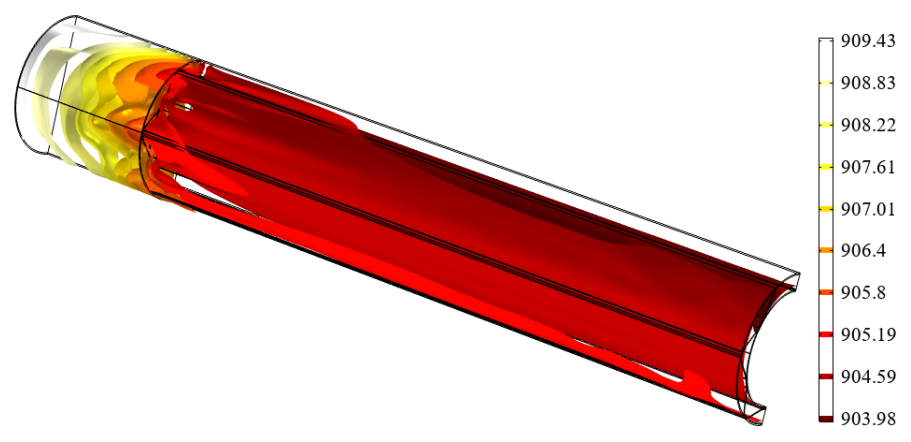

(a) Model 1

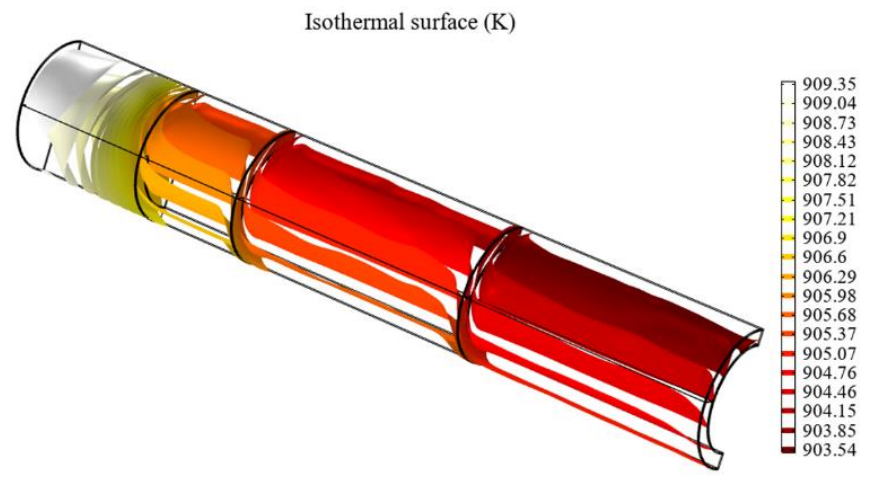

(b) Model 2

Fig. 6: Isothermal surface inside the annular heat pipe

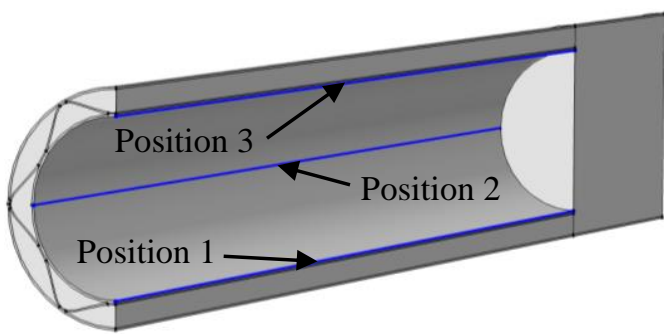

Fig. 7: Positions of temperature distribution comparison 
The isothermal performance of the annular part at the front end of the heat pipe was good, and the liquid pool part about 5-6 K higher than the annular part. It can be seen from the figure that the model 2 was divided into three sections, temperature distribution in each section was relatively uniform, the temperature difference was about $1.2 \mathrm{~K}$, the difference between the first section and the second section at the same height was about $0.5 \mathrm{~K}$, and the temperature in the third section was large. The temperature change of the inner diameter of the heat pipe was the most obvious at the connection wick and the connection with the liquid pool. Because the radial wick blocks the flow of working fluid vapor in three sections, and the area of condensation section is different made the temperature distribution of three areas different.

For the field of measurement, the isothermal performance at the condensation section is more important. The temperature distribution at different positions on the condensation section were compared. The positions were shown in Fig. 7. Temperature distribution in different positions of condensation section were shown in Fig. 8.

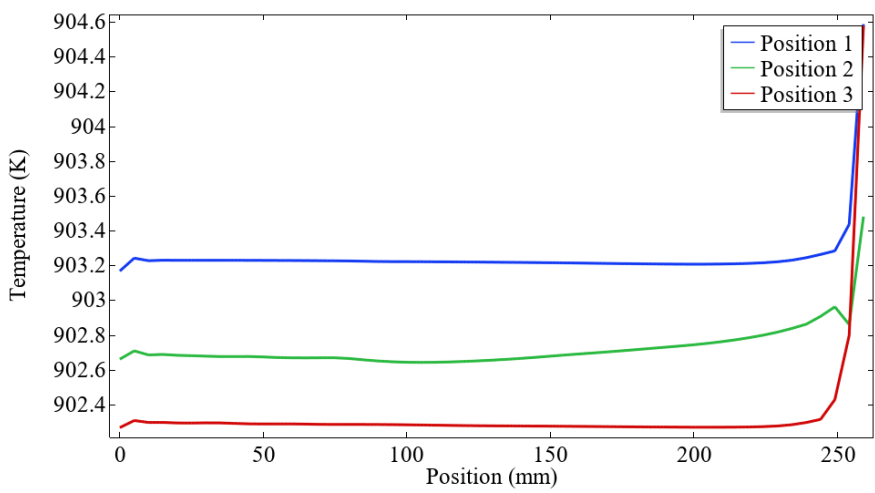

(a) Model 1

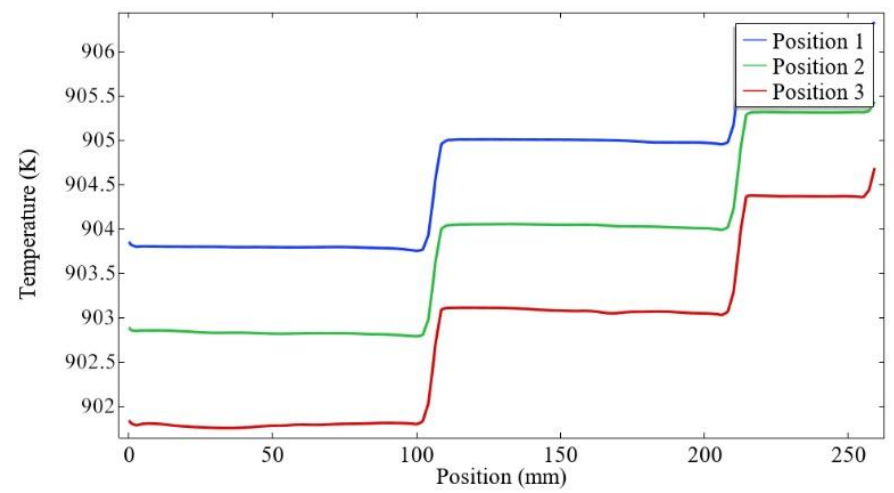

(b) Model 2

Fig. 8: Temperature distribution in different positions of condensation section

Affected by the gravity, the temperature at the high position of the annular part of the heat pipe is slightly lower than that at the low position, and the temperature difference is within 1-2 K. Although the axial direction connection wick structure will block the movement of the vapor in the vertical direction, but there is a connection of the liquid pool, and model 2 is completely divided into three parts. So the temperature difference of model 1 between different height is lower than model 2.

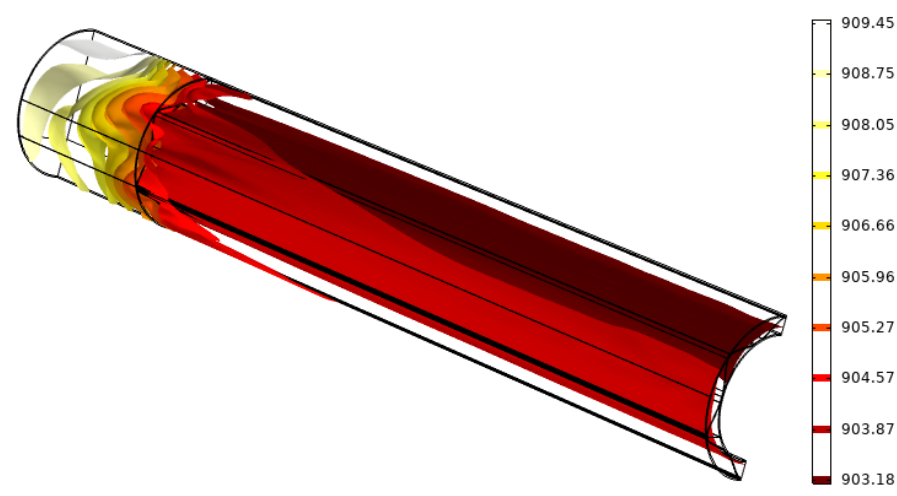

(a) Isothermal surface

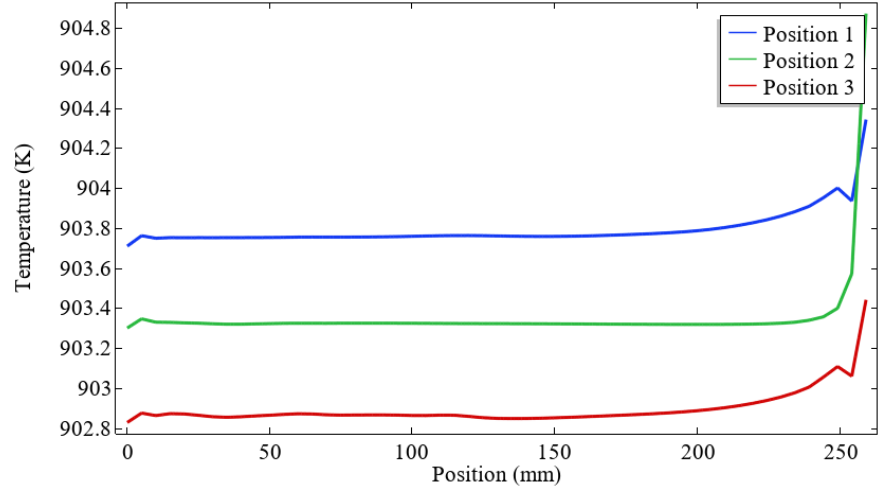

(b) Temperature distribution in different positions

Fig. 9: Temperature distribution of model 3

The temperature distribution of model 3 was shown in Fig. 9. Compare the Fig. 9 with Fig. 7(a), Fig. 8(a), when the position of the wick was rotated $60^{\circ}$, the isothermal surface inside the heat pipe is also rotated about $60^{\circ}$, at the outlet of 
the liquid pool, the isothermal surface distribution is obviously the same as the form of the wick. The temperature difference at three position between model 1 and model 3 were $0.4 \mathrm{~K}, 0.7 \mathrm{~K}$ and $0.4 \mathrm{~K}$ respectively, because the vapor chamber change to the connection point of wick at position 2 when the position of the wick was rotated $60^{\circ}$, and change at position 1 and position 3 were opposite. So the influence of the wick on the vapor flow will affect the vapor temperature distribution.

More conditions need to be simulated, such as different porosity, permeability, connection position of wicks and inclination angle of heat pipe. And we will make the same heat pipe as the model for experiment to compare the simulation results.

\section{Conclusion}

The present study has designed a concentric annular heat pipe, two type connection wick structures, and built a threedimensional symmetrical model. The isothermal performance of the annular part at the front end of the heat pipe was good, the temperature of liquid pool part was about 5-6 K higher than the annular part, and the isothermal surface distribution is obviously the same as the form of the wick at the outlet of the liquid pool. The influence of the wick on the vapor flow will affect the vapor temperature distribution. Both the axial direction connection wick structure and radial direction connection wick structure will block the flow of working fluid vapor, but the liquid pool can connect each vapor chamber parts at axial direction connection wick structure. So the isothermal performance of axial direction connection wick structure is better than radial direction connection wick structure. The isothermal surface will rotate with the wick because the axial direction connection wick structure is not centrosymmetric and affected by gravity.

\section{Acknowledgements}

This work was supported by the National Key R\&D Program of China [grant number 2017YFF0205901].

\section{Nomenclature}

$c_{p} \quad$ Specific heat capacity of mixture, $\mathrm{J} /(\mathrm{kg} \cdot \mathrm{K})$

$c_{p l} \quad$ Specific heat capacity of liquid, $\mathrm{J} /(\mathrm{kg} \cdot \mathrm{K})$

$c_{p w} \quad$ Specific heat capacity of heat pipe wall, $\mathrm{J} /(\mathrm{kg} \cdot \mathrm{K})$

$c_{p v} \quad$ Specific heat capacity of vapor, $\mathrm{J} /(\mathrm{kg} \cdot \mathrm{K})$

$k \quad$ Thermal conductivity of mixture, $\mathrm{W} /(\mathrm{m} \cdot \mathrm{K})$

$k_{l} \quad$ Thermal conductivity of liquid, $\mathrm{W} /(\mathrm{m} \cdot \mathrm{K})$

$k_{w} \quad$ Thermal conductivity of heat pipe wall, $\mathrm{W} /(\mathrm{m} \cdot \mathrm{K})$

$k_{v} \quad$ Thermal conductivity of vapor, $\mathrm{W} /(\mathrm{m} \cdot \mathrm{K})$

$K \quad$ Permeability, $\mathrm{m}^{2}$

$m_{l v} \quad$ Mass source term, $\mathrm{kg} /\left(\mathrm{m}^{3} \cdot \mathrm{s}\right)$

Greek Symbols

$\Delta H_{l v} \quad$ Latent heat, $\mathrm{kJ} / \mathrm{kg}$

$\varepsilon \quad$ Porosity,

$\rho$ Density of mixture, $\mathrm{kg} / \mathrm{m}^{3}$

$\rho_{l} \quad$ Density of vapor, $\mathrm{kg} / \mathrm{m}^{3}$

$\rho_{v} \quad$ Density of liquid, $\mathrm{N} / \mathrm{m}$ $d_{w} \quad$ Diameter of wick wire, $\mathrm{m}$

$f_{\text {cond }}$ Mass transfer coefficient in condensation, $1 / \mathrm{s}$

$f_{\text {evap }}$ Mass transfer coefficient in evaporation, $1 / \mathrm{s}$

g Acceleration of gravity, $\mathrm{m} / \mathrm{s}^{2}$

$N \quad$ Mesh number

$p \quad$ Pressure, $\mathrm{Pa}$

$T$ Temperature, $\mathrm{K}$

$t$ Time, $\mathrm{s}$

u Velocity, $\mathrm{m} / \mathrm{s}$

$\mu \quad$ Viscosity of mixture, $\mathrm{N} / \mathrm{m}$

$\mu_{l} \quad$ Viscosity of vapor, $\mathrm{N} / \mathrm{m}$

$\mu_{v} \quad$ Viscosity of liquid, N/m

$\phi_{l} \quad$ Volume fraction of vapor

$\phi_{v} \quad$ Volume fraction of liquid

Subscripts

$l \quad$ Liquid

$v \quad$ Vapor

$w \quad$ Wall 


\section{References}

[1] H. Hassan and S. Harmand, "An experimental and numerical study on the effects of the flat heat pipe wick structure on its thermal performance," Heat Transf. Eng., vol. 36, no. 3, pp. 278-289, 2015.

[2] D. S. Jang, D. Kim, S. H. Hong and Y. Kim, "Comparative thermal performance evaluation between ultrathin flat plate pulsating heat pipe and graphite sheet for mobile electronic devices at various operating conditions," Appl. Therm. Eng., vol. 149, pp. 1427-1434, 2019.

[3] M. H. Kusuma, N. Purta, A. R. Antariksawan, R. A. Koestoer, S. Widodo, S. Ismarwanti and B. T. Verlambang, "Passive cooling system in a nuclear spent fuel pool using a vertical straight wickless-heat pipe," Int. J. Therm. Sci., vol. 126, pp. 162-171, 2018.

[4] K. K. Panda, I. V. Dulera and A. Basak, "Numerical simulation of high temperature sodium heat pipe for passive heat removal in nuclear reactors," Nucl. Eng. Des., vol. 323, pp. 376-385, 2017.

[5] S. Y. Chen, H. T. Han, J. T. Shi, Q. Lu, L. F. Hu and B. C. Ai, "Applications of sodium/GH4099 heat pipes for nose cap cooling," Microgravity Sci. Technol., vol. 31, no. 4, pp. 417-424, 2019.

[6] S. Khairnasov, C. E. Andraka, V. Baturkin, V. Zaripov and O. Nishchyk, "Development of advanced high porosity wicks for the high temperature heat pipes of concentrating solar power," Appl. Therm. Eng., vol. 126, pp. 1170-1176, 2017.

[7] P. Marcarino and A. Merlone, "Gas-controlled heat-pipes for accurate temperature measurements," Appl. Therm. Eng., vol. 23, pp. 1145-1152, 2003.

[8] A. Merlone, S. Giunta and A. Tiziani, "A new mercury gas-controlled heat pipe for temperature amplifier and as calibration facility," Int. J. Thermophys., vol. 29, pp. 1876-1886, 2008.

[9] X. K. Yan, J. T. Zhang, A. Merlone, Y. Duan and W. Wang, "NIM gas controlled sodium heat pipe," in Proceedings of the 9th International Temperature Symposium on Temperature - Its Measurement and Control in Science and Industry, Los Angeles, CA, 2012, vol. 8, pp. 834-839.

[10] F. Bertiglia, L. Iacomini, F. Moro, and A. Merlone, "Comparison of two potassium-filled gas-controlled heat pipes," Int. J. Thermophys., vol. 36, pp. 3393-3403, 2015.

[11] S. Giunta, A. Merlone, S. Marenco, P. Marcarino and A. Tiziani, "Capabilities of a new pressure controller for gascontrolled heat pipes," Int. J. Thermophys., vol. 29, pp. 1887-1895, 2008.

[12] A. Nouri-Borujerdi and M. Layeghi, "A numerical analysis of vapor flow in concentric annular heat pipes," J. Fluids Eng.-Trans. ASME, vol. 126, pp. 442-448, 2004.

[13] J. Zhao, D. Z. Yuan, D. W. Tang and Y. Y. Jiang, "Heat transfer characteristics of a concentric annular high temperature heat pipe under anti-gravity conditions," Appl. Therm. Eng., vol. 148, pp. 817-824, 2019.

[14] Y. O. Parent, H. S. Caram and R. W. Coughlin, "Tube-wall catalytic reactor cooled by an annular heat pipe," AICHE J., vol. 29, no. 3, pp. 443-451, 1983.

[15] M. Ahmad, N. P. Ahn, R. David and B. Kamelia, "Concentric annular heat pipe characterisation analysis for a drying application," Appl. Therm. Eng., vol. 149, pp. 275-286, 2019.

[16] C. Jeehoon, Y. Yuan, A. B. Diana and K. Hwankook, "Design, construction, and performance testing of an isothermal naphthalene heat pipe furnace," Rev. Sci. Instrum., vol. 85, pp.1-6, 2014.

[17] K. S. Gam, "A stable microcomputer-controlled heat pipe furnace and test of new noble metal thermocouples," Measurement, vol. 18, no. 2, pp. 101-108, 1996.

[18] X. K. Yan, Y. N. Duan, C. F. Ma and Z. F. Lv, "Construction of sodium heat-pipe furnaces and the isothermal characteristics of the furnaces," Int. J. Thermophys, vol. 32, pp. 494-504, 2011.

[19] A. B. Solomon, K. Ramachandran, L. G. Asirvatham and B. C. Pillai, "Numerical analysis of a screen mesh wick heat pipe with Cu/water nanofluid," Int. J. Heat Mass Transf., vol. 75, pp. 523-533, 2014.

[20] B. Fadhl, L. C. Wrobel and H. Jouhara, "Numerical modelling of the temperature distribution in a two-phase closed thermosiphon," Appl. Therm. Eng., vol. 60, pp. 122-131, 2013.

[21] W. H. Lee, "Pressure iteration scheme for two-phase flow modelling," in Proceedings of the IEEE Engineering in Medicine and Biology Society Annual Conference, Washington D. C., 1980, pp. 407-431. 